\title{
Prevalence of metastases within the hypothalamic-pituitary area in patients with brain metastases
}

\author{
Stefan Janssen ${ }^{1,2,7^{*}}$, Preena Mehta $^{1 \dagger}$, Tobias Bartscht ${ }^{3}$, Sebastian M. Schmid ${ }^{4,5}$, Fabian B. Fahlbusch ${ }^{6}$ and Dirk Rades ${ }^{1}$
}

\begin{abstract}
Aim: To quantify the prevalence of brain metastases involving the hypothalamic-pituitary (HT-P) area. Introduction: Cognitive impairment and fatigue are common side effects of whole brain irradiation (WBI) comprising the quality of life (QoL) for survivors. While the former is related to radiation-induced hippocampal injury, the latter could be secondary to hormonal disbalance as a consequence of radiation of the HT-P area. Thus, sparing both regions from higher irradiation doses could reduce these sequelae.
\end{abstract}

Methods: $T 1$ contrast medium enhanced magnetic resonance imaging (MRI) scans of 865 patients with brain metastases (4,280 metastases) were reviewed. HT-P area was individually contoured with a margin of $5 \mathrm{~mm}$ in order to evaluate the prevalence of brain metastases in this region.

Results: Involvement of the hypothalamic region was found in 26 patients (involvement rate of 3\% for patients and $1 \%$ for metastases), involvement of the pituitary gland in 9 patients ( $1 \%$ for patients and $<1 \%$ for metastases). Binary logistical regression analysis revealed the presence of $>10$ brain metastases as the only factor associated with hypothalamic involvement while no distinct factor was associated with an involvement of the pituitary gland.

Conclusion: The low prevalence of metastases within the HT-P area in patients with brain metastases calls for further studies examining whether sparing of this region might improve patients QoL.

Keywords: Brain metastases, Whole brain radiotherapy, Hormonal impairment, Hypothalamus/pituitary gland sparing, QoL

\section{Introduction}

Brain metastases are the most common intracranial tumors and occur in approximately 10 to $30 \%$ of adult cancer patients [1]. Even in modern times of high precision radiotherapy, whole brain irradiation (WBI) is an option for patients with multiple brain metastases or as prophylactic cranial irradiation (PCI) in patients with small-cell lung cancer (SCLC). However, cognitive impairment and fatigue are common long-term side effects that relevantly comprise the quality of life (QoL) for survivors [2]. Hippocampal neural stem-cell injury due to irradiation might play a mechanistic role in memory decline

\footnotetext{
* Correspondence: st-janssen@gmx.ne

${ }^{\dagger}$ S. Janssen and P. Mehta contributed equally to this work.

${ }^{1}$ Department of Radiation Oncology, University of Lübeck, Lübeck, Germany

${ }^{2}$ Private Practice of Radiation Oncology, Hannover, Germany

Full list of author information is available at the end of the article
}

[3] while affection of the hypothalamic-pituitary (HT-P) axis further promotes symptoms like fatigue [4]. Impaired HT-P axis activity is common after radiotherapy of brain tumors [5-8] as well as head-and-neck cancer [9-14]. Although the degree of irradiation damage is dose-dependent [7], relevant impairment of the HT-P axis can already occur upon low doses of $\sim 18$ Gy [15].

Long-term endocrine follow-up data from adult survivors of childhood and adolescent cancer $[16,17]$ who received WBI (mainly 24 Gy) show that the vast majority of patients developed some kind of HT-P insufficiency. The hormonal deficiency typically follows a predictable course [15] with growth-hormone (GH) secretion being the most sensitive to radiotherapy. In fact, it might be the first or only hormone deficiency apparent [16]. Clinically, radiation-induced GH deficiency in adults mimics signs and symptoms of adult GH deficiency syndrome,

(c) The Author(s). 2019 Open Access This article is distributed under the terms of the Creative Commons Attribution 4.0 International License (http://creativecommons.org/licenses/by/4.0/), which permits unrestricted use, distribution, and 
in particular increased fatigue and impaired QoL [18]. Thus, radiation-related endocrinopathy affects the patient not only physiologically, but also psychologically [16]. Other WBI-associated HT-P endocrinopathies include gonadotropin (follicle-stimulating hormone and luteinising hormone) deficiency, thyroid-stimulating hormone (TSH) deficiency, adrenocorticotropic hormone (ACTH) deficiency and hyperprolactinaemia [16].

As GH replacement therapy might improve the above symptoms [18] among survivors of childhood acute lymphoblastic leukemia and CNS tumors, provocative endocrine follow-up testing for isolated GH deficiency, e.g. by insulin tolerance test (ITT), is crucial to establish a robust diagnosis for the timely implementation of GH replacement therapy [17]. In this context, a priori avoidance of radiation-induced injury of the HT-P region might pose a feasible alternative for certain patients, especially in the palliative setting of brain metastases where preservation of QoL is the main objective. In accordance to a phase II study showing better memory function QoL when sparing hippocampus area during WBI [19], sparing the HT-P area during WBI may result in better endocrine and functional outcome.

To assess the practicability of HT-P sparing in patients with brain metastases detailed knowledge on the prevalence of metastatic lesions within this potential avoidance region is crucial. As scientific data is scarce to date, the present study aims to systematically assess the prevalence of HT-P metastases in patients with brain metastases.

\section{Methods}

Pre-treatment gadolinium-enhanced T1-weighted magnetic resonance image (MRI) datasets of 865 patients with brain metastases from the years 2014-2018 were reviewed at the University of Luebeck, Germany. The HT-P area was contoured on axial planes for each patient as described previously by others $[20,21]$. In short, minimal requirements for sufficient contouring and delineation were as following: CT images (axial planes) were fused to images obtained via T1weighted MRI images (gadolinium contrast enhanced) acquired on $1.5 \mathrm{~T}$ resonance scans with a slice thickness of $1.5 \mathrm{~mm}$. The hypothalamus and pituitary gland (including the pituitary stalk) were contoured on T1-weighted axial MRI sequences and a margin of $5 \mathrm{~mm}$ was added (see Fig. 1) $[20,21]$.

We excluded examinations not fulfilling a minimum of standards e.g. providing only one MRI sequence, blurred sequences, slice thickness $>1.5 \mathrm{~mm}$ or no contrast medium.

For each patient, data regarding the primary tumor type, age at the diagnosis of brain metastases, gender, maximum size of brain metastases, and the total number of brain metastases was recorded (Table 1). In case of more than 30 brain metastases, the number was rated as $\geq 30$. Patients with leptomeningeal disease and previous brain irradiation were excluded from analysis.

According to previously published analysis on hippocampal involvement, the number of metastases within 5 $\mathrm{mm}$ from the pituitary gland as well as from the hypothalamus was correlated with the above-mentioned variables. A binary logistical regression model using a backward step-wise approach was developed, and a two-sided $p$ value of $<0.05$ was considered statistically significant [22]. For the logistic regression analysis of the number of brain metastasis, we chose to analyze $n=1-3$ vs. $n>10$, as several randomized studies support the use of radiosurgery in 1-3 lesions [23, 24]. Moreover, some authors have shown a survival difference for this threshold [25]. Additionally, the Graded Prognostic Assessment (GPA) from the Radiation Therapy Oncology Group (RTOG) and the diagnosisspecific GPA score (ds-GPA) also differentiates between $>3$ and less than three metastases [26, 27].

The protocol of this retrospective study was approved by the local ethics committee of the University of Luebeck (\# 19-075A).

\section{Results}

A total number of 4,280 brain metastases in 865 patients were identified with a mean of 5 metastases per patient.

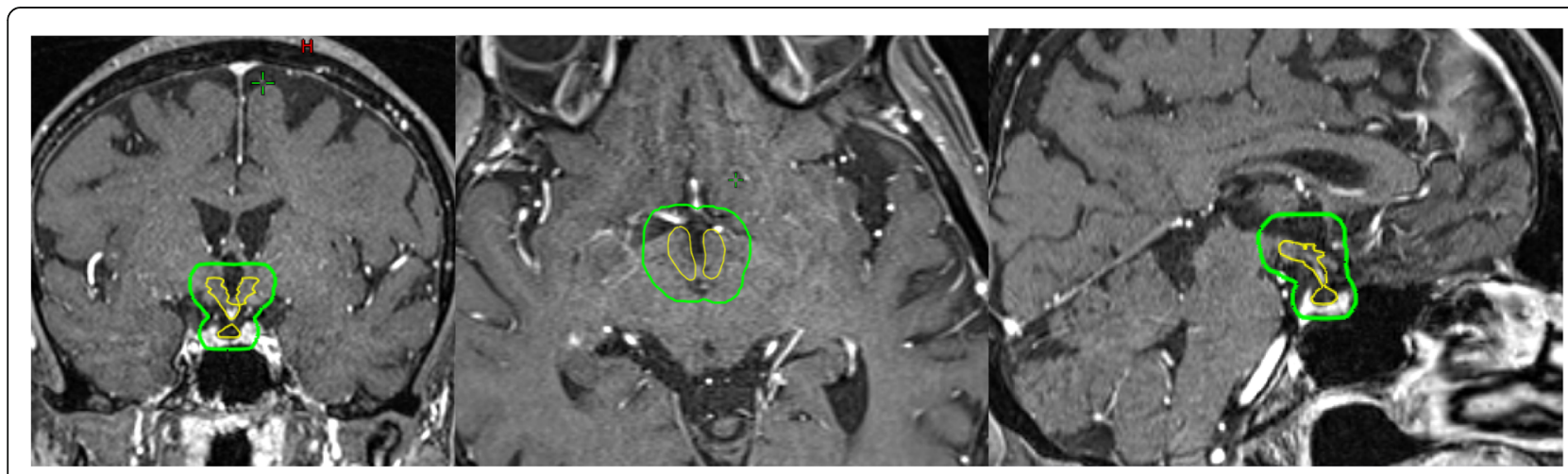

Fig. 1 Contouring example of the HT-P axis (gadolinium enhanced T1 MRI) 
Table 1 Patient characteristics (NSCLC: non-small cell lung cancer, SCLC: small cell lung cancer)

\begin{tabular}{ll}
\hline Sex & \\
male & $434(50 \%)$ \\
female & $431(50 \%)$ \\
Age & Mean: 64 years (29-90) \\
$<64$ years & $424(49 \%)$ \\
$>64$ years & $441(51 \%)$ \\
Primary tumor entity & involvement of hypothalamus and pituitary gland \\
NSCLC & $401(46 \%) 13 / 401$ \\
SCLC & $121(14 \%) 8 / 121$ \\
Breast & $106(12 \%) 5 / 106$ \\
Melanoma & $62(7 \%) 1 / 62$ \\
Renal & $27(3 \%) 0 / 27$ \\
Colorectal & $35(4 \%) 2 / 35$ \\
Other & $113(13 \%) 6 / 113$ \\
Number of & Mean: 5, median: 2 (range: $1-30)$ \\
metastases & \\
Maximum size & Mean: $2 \mathrm{~cm}$, median: $1.8 \mathrm{~cm}$ (range: $0.2 \mathrm{~cm}$ to \\
& $11 \mathrm{~cm})$
\end{tabular}

Individual maximum size of metastases ranged from 0.2 to $11 \mathrm{~cm}$ (median: $1.8 \mathrm{~cm}$ ). Patients mean age was 64 years (range: 29-90 years) and the primary tumor entity was non-small cell lung cancer (NSCLC) in $46 \%$ of the patients. Patient and disease characteristics are summarized in Table 1. Involvement of the hypothalamus region (hypothalamus $+5 \mathrm{~mm}$ ) was found in 26 patients translating to HT involvement of $\sim 3 \%$ of patients and $1 \%$ of all metastases. Involvement of the pituitary region (pituitary gland $+5 \mathrm{~mm}$ ) was observed in 9 patients, i.e. $1 \%$ of all patients and $<1 \%$ of all metastases, respectively. Binary logistical regression models revealed a high number of metastases, i.e. $>10$ vs. $<3$ metastases as the only factor significantly associated with hypothalamic involvement $(p=0.0002$; Table 2). In contrast, examined factors were not related to the involvement of the pituitary gland region (Table 3).

\section{Discussion}

This retrospective analysis of 865 patients with a cumulative total of 4,280 brain metastases reveals that only 4\% of all metastases were located within the HT-P area. This study clearly extends our knowledge on the low prevalence of hypothalamic and pituitary region metastases.

Until now, most of current data were based on smaller studies, case reports, and reviews [28-34]. Marsh et al. reported on 155 retrospectively analyzed patients with a total of 935 brain metastases and only one case $(<1 \%)$ of pituitary involvement [29].

Metastases within the HT-P area are relatively rare and can arise from various tumors like thyroid carcinoma [28, 30,31], melanoma [32], breast cancer [33] and prostate cancer [34]. Smaller case series could not identify a specific tumor predisposing for hypothalamic/pituitary metastases. These observations are in line with the structured analysis of our large cohort. There is no specific tumor entity correlated with HT-P involvement.

Brain metastases are common for many cancers and can be treated with surgery, high precision radiotherapy or, in case of multiple metastases, WBI. Furthermore, PCI can be applied in patients with SCLC, respectively. Although beneficial for oncological treatment, WBI is accompanied with various side effects such as neurocognitive impairment, fatigue, and endocrine disorders, all resulting in reduced QoL.

The HT-P area is highly sensible for irradiation and impairment of the endocrine hypothalamus-pituitary axes is common after radiotherapy. The somatotropic axis is most vulnerable to irradiation damage and can occur after doses as low as 18 Gy [15] or even 10 Gy in children or young adults [35]. However, endocrine disturbance can further include all other hormonal axis, i.e. the corticotropic, thyreotropic, and gonadotropic axis on the level of the hypothalamus and/or pituitary, respectively. Long term survivors of cancer with radiotherapy for head-and-neck tumors developed a dysfunction of at least one hormonal axis (46\%), 24\% had impairment of two axes, and 3\% had a dysfunction in three axes [10].

Table 2 Logistic regression analysis for incidence of metastases within $5 \mathrm{~mm}$ of the hypothalamus

\begin{tabular}{llll}
\hline Variable & $\begin{array}{l}\text { Point } \\
\text { estimate }\end{array}$ & $\begin{array}{l}\text { 95\% Wald } \\
\text { confidence limits }\end{array}$ \\
\hline Age (age $>64$ years vs. <=64 years) & 2.019 & $0.845-4.824$ & 0.1140 \\
Sex (female vs. male) & 0.820 & $0.335-2.009$ & 0.6644 \\
Tumor type (NSCLC as reference) & & & 0.7543 \\
SCLC & 1.916 & $0.638-5.749$ \\
Breast & 1.427 & $0.327-6.219$ \\
Melanoma/renal/colorectal & 1.348 & $0.341-5.337$ \\
Maximal diameter (>=1.9 cm vs. <=1.8cm) & 2.146 & $0.899-5.125$ \\
Number of brain metastases (>10 vs. 1-3) & 6.668 & $2.643-16.827$ & 0.0854 \\
\hline
\end{tabular}


Table 3 Logistic regression analysis for incidence of metastases within $5 \mathrm{~mm}$ of the pituitary gland

\begin{tabular}{llll}
\hline Variable & $\begin{array}{l}\text { Point } \\
\text { estimate }\end{array}$ & $\begin{array}{l}95 \% \text { Wald } \\
\text { confidence limits }\end{array}$ & $p$-value \\
\hline Age (age $>$ 64 years vs. <=64 years) & 0.858 & $0.224-3.280$ & 0.8238 \\
Sex (female vs male) & 1.722 & $0.380-7.794$ & 0.4805 \\
Tumor type (NSCLC as reference) & & & 0.8121 \\
SCLC & 0.585 & $0.066-5.184$ & $0.189-6.614$ \\
Breast & 1.118 & $0.044-3.417$ \\
Melanoma/renal/colorectal & 0.389 & $0.518-8.576$ & $0.427-13.601$ \\
Maximal diameter (>=1.9 cm vs. <=1.8 cm) & 2.108 & 0.2976 \\
Number of brain metastases (>10 vs 1-3) & 2.410 & 0.4892 \\
\hline
\end{tabular}

Other studies report on hypopituitarism of at least one axis in up to $93 \%$ of patients treated with radiotherapy for nasopharynx cancer [12] and Madaschi et al. revealed clinically relevant hormone deficiency for the somatotropic (29\%), corticotropic (22\%), thyreotripic (14\%) and gonadotropic (4\%) axis in patients irradiated for extrasellar brain tumors [36]. Together, the overall prevalence of any degree of hypopituitarism is considered $25-100 \%$ in patients treated for nasopharynx cancer and $37-77 \%$ in patients with intracerebral tumors [14]. Of note, irradiation induced impairment of HP-axes appears to be a late onset sequela accompanied by a progression in severity over time but can also appear within the first year after radiotherapy [14].

All mentioned side effects after radiotherapy are dosedependent $[9,10,15,37-40]$ with a clearly increased incidence of HT-P axes impairments at doses above $30 \mathrm{~Gy}$. However, there are no data defining a clinically significant threshold [39]. Accordingly, established dose-fractionation concepts in WBI $(10 \times 3$ Gy, $15 \times 2.5$ Gy or $20 \times 2$ Gy $)$ are within the dose range of potential impairment.

It is tempting to speculate that avoiding irradiation of the HT-P area by HT-P sparing WBI technique might lower endocrine and neurocognitive burden of classical WBI and preserve patients QoL. Recently, the groups of Fan and Marsh, respectively, showed that sparing of the hippocampus and the HT-P axis during WBI is technically feasible [20, 41]. However, the question remains whether the oncological prognosis is acceptable when sparing HT-P area during WBI. The reported low prevalence below $4 \%$ of HT$P$ involvement in our large cohort of patients with brain metastases argues for further studies to justify the concept of HT-P area sparing WBI in analogy to the hippocampus sparing technique recently introduced by Gondi and colleagues [19]. On the background of a low risk of $8.6 \%$ for hippocampal metastases in 371 patients with brain metastases [22], hippocampus sparing WBI has been established in many radiation oncology centers worldwide.
Further supporting oncological safety of a HT-P area sparing WBI concept, the only predictor for involvement of the hypothalamus region was a total number of more than 10 brain metastases. Interestingly, Gondi et al. excluded patients with more than 10 brain metastases inherently from their analysis [22]. Considering the exclusion criteria of Gondi et al. and the results of our present study, we would recommend a HT-P sparing approach only in patients with less than 10 brain metastases. Although stereotactic radiosurgery (SRS) or fractionated stereotactic radiotherapy (FSRT) are increasingly applied concepts in patients with a limited number of brain metastases, there are still clinical indications for therapeutic and prophylactic WBI. Reducing potential side effects by a HT-P sparing WBI approach could improve patient's endocrine outcome and QoL.

To our knowledge, our study involved the largest cohort regarding the assessment of the prevalence of HT-P area metastases by now. Our findings are somewhat limited by the fact that data were analyzed retrospectively and we cannot report on endocrine function in our patients. Moreover, our study did not cover radio-surgical approaches or their combination with WBI. Also, we did not examine the total volume of metastasis (as opposed to the diameter of the largest lesion) as proxy for intracranial tumor burden, which might additionally pose a potential risk factor for HT-P region involvement and decision making in HT-P sparing radiotherapy.

However, we are confident that the low prevalence of HT-P metastases seems worthy of further clinical evaluation of a sparing approach in selected patients. Although potential benefits of HT-P sparing WBI appear likely, a prospective intervention study is needed.

\section{Conclusion}

Only $4 \%$ of brain metastases in this large study cohort of 865 patients with 4,280 metastases were located within the HT-P area. HT-P radiation-sparing might pose a treatment option for patients with a limited number of brain metastases and those without involvement of the HT-P 
region analogue to current hippocampus sparing approaches. As palliative therapy, WBI treatment courses should aim to improve or at least stabilize QoL. A prospective study evaluating potential endocrine and functional benefit of such a sparing approach during WBI is planned.

\section{Abbreviations}

ACTH: Adrenocorticotropic hormone; FSRT: Fractionated stereotactic radiotherapy; GH: Growth hormone; GPA: Graded Prognostic Assessment; HTP: Hypothalamic-pituitary; ITT: Insulin tolerance test; MRI: Magnetic resonance imaging; NSCLC: Non-small cell lung cancer; PCI: Prophylactic cranial irradiation; QoL: Quality of life; RTOG: Radiation Therapy Oncology Group; SCLC: Small cell lung cancer; SRS: Stereotactic radiosurgery; TSH: Thyroidstimulating hormone; WBI: Whole brain irradiation

\section{Acknowledgements}

None

\section{Authors' contributions}

All authors read and approved the final version of the manuscript. Idea and conception: SJ, DR. Data collection: SJ, PM, TB, SS; DR. Data interpretation: SJ, DR, PM, FF. Manuscript writing: SJ, PM, TB, SS, DR, FF.

\section{Funding}

None

Availability of data and materials

Not applicable, entire data is shown within the manuscript / tables

\section{Ethics approval and consent to participate}

The protocol of this retrospective study was approved by the local ethics committee of the University of Luebeck (\# 19-075A).

\section{Consent for publication}

Not applicable

\section{Competing interests}

The authors declare that they have no competing interests

\begin{abstract}
Author details
${ }^{1}$ Department of Radiation Oncology, University of Lübeck, Lübeck, Germany. ${ }^{2}$ Private Practice of Radiation Oncology, Hannover, Germany. ${ }^{3}$ Department of Haematology and Oncology, University of Lübeck, Lübeck, Germany. ${ }^{4}$ Department of Endocrinology, University of Lübeck, Lübeck, Germany. ${ }^{5}$ German Center for Diabetes Research (DZD), Neuherberg, Germany. ${ }^{6}$ Department of Pediatrics and Adolescent Medicine, Friedrich-Alexander-University of Erlangen-Nürnberg, Erlangen, Germany. ${ }^{7}$ Klinik für Strahlentherapie, Universität zu Lübeck, Ratzeburger Allee 160, Haus 40, 23562 Lübeck, Germany.
\end{abstract}

Received: 6 May 2019 Accepted: 15 July 2019

Published online: 27 August 2019

\section{References}

1. Khuntia D, Brown P, Li J, Mehta MP. Whole-brain radiotherapy in the management of brain metastasis. J Clin Oncol. 2006;24(8):1295-304.

2. Steinmann D, Paelecke-Habermann $Y$, Geinitz $H$, Aschoff $R$, Bayerl A, Bölling T, Bosch E, Bruns F, Eichenseder-Seiss U, Gerstein J, Gharbi N, Hagg J, Hipp M, Kleff I, Müller A, Schäfer C, Schleicher U, Sehlen S, Theodorou M, Wypior HJ, Zehentmayr F, van Oorschot B, Vordermark D. Prospective evaluation of quality of life effects in patients undergoing palliative radiotherapy for brain metastases. BMC Cancer. 2012;12:283.

3. Gondi V, Tomé WA, Mehta MP. Why avoid the hippocampus? A comprehensive review. Radiother Oncol. 2010:97(3):370-6.

4. Darzy $\mathrm{KH}$, Shalet SM. Hypopituitarism following radiotherapy. Pituitary. 2009:12(1):40-50.

5. Constine LS, Woolf PD, Cann D, Mick G, McCormick K, Raubertas RF, et al. Hypothalamic-pituitary dysfunction after radiation for brain tumors. N Engl J Med. 1993;328(2):87-94.
6. Merchant TE, Goloubeva O, Pritchard DL, Gaber MW, Xiong X, Danish RK, et al. Radiation dose-volume effects on growth hormone secretion. Int J Radiat Oncol Biol Phys. 2002;52(5):1264-70.

7. Elson A, Bovi J, Kaur K, Maas D, Sinson G, Schultz C. Effect of treatment modality on the hypothalamic-pituitary function of patients treated with radiation therapy for pituitary adenomas: hypothalamic dose and endocrine outcomes. Front Oncol. 2014;4:73.

8. Kyriakakis N, Lynch J, Orme SM, Gerrard G, Hatfield P, Loughrey C, et al. Pituitary dysfunction following cranial radiotherapy for adult-onset nonpituitary brain tumours. Clin Endocrinol. 2016;84(3):372-9.

9. Powell C, Schick U, Morden JP, Gulliford SL, Miah AB, Bhide S, et al. Fatigue during chemoradiotherapy for nasopharyngeal cancer and its relationship to radiation dose distribution in the brain. Radiother Oncol. 2014;110(3):416-21.

10. Löfdahl E, Berg G, Johansson KA, Zachrisson ML, Malmgren H, Mercke $\mathrm{C}$, et al. Compromised quality of life in adult patients who have received a radiation dose towards the basal part of the brain. A casecontrol study in long-term survivors from cancer in the head and neck region. Radiat Oncol. 2012;7:179.

11. Seland M, Bjøro T, Furre T, Schreiner T, Bollerslev J, Fosså SD, et al. Hormonal dysfunction is frequent in cancer survivors treated with radiotherapy to the head and neck region. J Cancer Surviv. 2015:9(4):630-40.

12. Ipekci SH, Cakir M, Kiyici A, Koc O, Artac M. Radiotherapy-induced hypopituitarism in nasopharyngeal carcinoma: the tip of an iceberg. Exp Clin Endocrinol Diabetes. 2015;123(7):411-8.

13. Bhandare N, Kennedy L, Malyapa RS, Morris CG, Mendenhall WM. Hypopituitarism after radiotherapy for extracranial head and neck cancers. Head Neck. 2008;30(9):1182-92.

14. Appelman-Dijkstra NM, Malgo F, Neelis KJ, Coremans I, Biermasz NR, Pereira AM. Pituitary dysfunction in adult patients after cranial irradiation for head and nasopharyngeal tumours. Radiother Oncol. 2014;113(1):102-7.

15. Darzy KH. Radiation-induced hypopituitarism after cancer therapy: who, how and when to test. Nat Clin Pract Endocrinol Metab. 2009:5(2):88-99.

16. Tonorezos ES, Hudson MM, Edgar AB, Kremer LC, Sklar CA, Wallace WH, Oeffinger KC. Screening and management of adverse endocrine outcomes in adult survivors of childhood and adolescent cancer. Lancet Diabetes Endocrinol. 2015:3(7):545-55.

17. Follin C, Erfurth EM. Long-term effect of cranial radiotherapy on pituitaryhypothalamus area in childhood acute lymphoblastic leukemia survivors. Curr Treat Options in Oncol. 2016;17(9):50.

18. Murray RD, Darzy KH, Gleeson HK, Shalet SM. GH-deficient survivors of childhood cancer: GH replacement during adult life. J Clin Endocrinol Metab. 2002;87(1):129-35.

19. Gondi V, Pugh SL, Tome WA, Caine C, Corn B, Kanner A, et al. Preservation of memory with conformal avoidance of the hippocampal neural stem-cell compartment during whole-brain radiotherapy for brain metastases (RTOG 0933): a phase II multi-institutional trial. J Clin Oncol. 2014;32(34):3810-6.

20. Fan XW, Wang JQ, Wu JL, Wang HB, Wu KL. Simultaneously avoiding the hippocampus and hypothalamic-pituitary axis during whole brain radiotherapy: a planning study. Med Dosim. 2018;44(2):130-5.

21. Scoccianti S, Detti B, Gadda D, Greto D, Furfaro I, Meacci F, et al. Organs at risk in the brain and their dose-constraints in adults and in children: a radiation oncologist's guide for delineation in everyday practice. Radiother Oncol. 2015;114(2):230-8.

22. Gondi V, Tome WA, Marsh J, Struck A, Ghia A, Turian JV, et al. Estimated risk of perihippocampal disease progression after hippocampal avoidance during whole-brain radiotherapy: safety profile for RTOG 0933. Radiother Oncol. 2010;95(3):327-31.

23. Andrews DW, Scott CB, Sperduto PW, Flanders AE, Gaspar LE, Schell MC, Werner-Wasik M, Demas W, Ryu J, Bahary JP, Souhami L, Rotman M, Mehta MP, Curran WJ Jr. Whole brain radiation therapy with or without stereotactic radiosurgery boost for patients with one to three brain metastases: phase III results of the RTOG 9508 randomised trial. Lancet. 2004;363(9422):1665-72.

24. Kocher M, Soffietti R, Abacioglu U, Villà S, Fauchon F, Baumert BG, Fariselli L, Tzuk-Shina T, Kortmann RD, Carrie C, Ben Hassel M, Kouri M, Valeinis E, van den Berge D, Collette S, Collette L, Mueller RP. Adjuvant whole-brain radiotherapy versus observation after radiosurgery or surgical resection of one to three cerebral metastases: results of the EORTC 22952-26001 study. J Clin Oncol. 2011;29(2):134-41.

25. Meyners T, Heisterkamp C, Kueter JD, Veninga T, Stalpers LJ, Schild SE, Rades D. Prognostic factors for outcomes after whole-brain irradiation 
of brain metastases from relatively radioresistant tumors: a retrospective analysis. BMC Cancer. 2010;10:582.

26. Sperduto PW, Berkey B, Gaspar LE, Mehta M, Curran W. A new prognostic index and comparison to three other indices for patients with brain metastases: an analysis of 1,960 patients in the RTOG database. Int J Radiat Oncol Biol Phys. 2008;70(2):510-4 Epub 2007 Oct 10.

27. Sperduto PW, Kased N, Roberge D, Xu Z, Shanley R, Luo X, Sneed PK, Chao ST, Weil RJ, Suh J, Bhatt A, Jensen AW, Brown PD, Shih HA, Kirkpatrick J, Gaspar LE, Fiveash JB, Chiang V, Knisely JP, Sperduto CM, Lin N, Mehta M. Summary report on the graded prognostic assessment: an accurate and facile diagnosis-specific tool to estimate survival for patients with brain metastases. J Clin Oncol. 2012;30(4):419-25.

28. Bhatoe HS, Badwal S, Dutta V, Kannan N. Pituitary metastasis from medullary carcinoma of thyroid: case report and review of literature. J Neuro-Oncol. 2008:89(1):63-7.

29. Marsh JC, Garg S, Wendt JA, Gielda BT, Turian JV, Herskovic AM. Intracranial metastatic disease rarely involves the pituitary: retrospective analysis of 935 metastases in 155 patients and review of the literature. Pituitary. 2010;13(3):260-5.

30. Barbaro D, Desogus N, Boni G. Pituitary metastasis of thyroid cancer. Endocrine. 2013;43(3):485-93.

31. Williams MD, Asa SL, Fuller GN. Medullary thyroid carcinoma metastatic to the pituitary gland: an unusual site of metastasis. Ann Diagn Pathol. 2008; 12(3):199-203.

32. McCutcheon IE, Waguespack SG, Fuller GN, Couldwell WT. Metastatic melanoma to the pituitary gland. Can J Neurol Sci. 2007;34(3):322-7.

33. Kurkjian C, Armor JF, Kamble R, Ozer H, Kharfan-Dabaja MA. Symptomatic metastases to the pituitary infundibulum resulting from primary breast cancer. Int J Clin Oncol. 2005;10(3):191-4.

34. Prpić M, Fröbe A, Zadravec $D$, Pažanin $L$, Jakšić B, Bolanča $A$, Kusić $Z$. Initial symptomatic pituitary metastasis in a patient with prostatefoamy gland carcinoma: tailoring safe and effective therapy. Acta Clin Croat. 2015;54(2):243-8.

35. Crowne E, Gleeson H, Benghiat H, Sanghera P, Toogood A. Effect of cancer treatment on hypothalamic-pituitary function. Lancet Diabetes Endocrinol. 2015;3(7):568-76.

36. Madaschi S, Fiorino C, Losa M, Lanzi R, Mazza E, Motta M, et al. Time course of hypothalamic-pituitary deficiency in adults receiving cranial radiotherapy for primary extrasellar brain tumors. Radiother Oncol. 2011;99(1):23-8.

37. Chemaitilly W, Li Z, Huang S, Ness KK, Clark KL, Green DM, et al. Anterior hypopituitarism in adult survivors of childhood cancers treated with cranial radiotherapy: a report from the St Jude lifetime cohort study. J Clin Oncol. 2015;33(5):492-500.

38. Pai HH, Thornton A, Katznelson L, Finkelstein DM, Adams JA, Fullerton BC, et al. Hypothalamic/pituitary function following high-dose conformal radiotherapy to the base of skull: demonstration of a dose-effect relationship using dose-volume histogram analysis. Int J Radiat Oncol Biol Phys. 2001:49(4):1079-92.

39. Gulliford SL, Miah AB, Brennan S, McQuaid D, Clark CH, Partridge M, et al. Dosimetric explanations of fatigue in head and neck radiotherapy: an analysis from the PARSPORT phase III trial. Radiother Oncol. 2012;104(2):205-12.

40. Sathyapalan T, Dixit S. Radiotherapy-induced hypopituitarism: a review. Expert Rev Anticancer Ther. 2012;12(5):669-83.

41. Marsh JC, Godbole RH, Herskovic AM, Gielda BT, Turian JV. Sparing of the neural stem cell compartment during whole-brain radiation therapy: a dosimetric study using helical tomotherapy. Int J Radiat Oncol Biol Phys. 2010;78(3):946-54

\section{Publisher's Note}

Springer Nature remains neutral with regard to jurisdictional claims in published maps and institutional affiliations.

Ready to submit your research? Choose BMC and benefit from:

- fast, convenient online submission

- thorough peer review by experienced researchers in your field

- rapid publication on acceptance

- support for research data, including large and complex data types

- gold Open Access which fosters wider collaboration and increased citations

- maximum visibility for your research: over $100 \mathrm{M}$ website views per year

At BMC, research is always in progress.

Learn more biomedcentral.com/submissions 